\title{
Fatal colitis associated with active systemic lupus erythematosus complicated by cytomegalovirus superinfection
}

\author{
Elisa Gravito-Soares, ${ }^{1,2}$ Marta Gravito-Soares, ${ }^{1,2}$ Maria Augusta Cipriano, ${ }^{3}$ \\ Pedro Amaro ${ }^{1}$
}

\section{'Department of}

Gastroenterology, Centro Hospitalar e Universitário de Coimbra, Coimbra, Portugal ${ }^{2}$ Faculty of Medicine, University of Coimbra, Coimbra, Portugal ${ }^{3}$ Department of Pathology, Centro Hospitalar e Universitário de Coimbra, Coimbra, Portugal

\section{Correspondence to Dr Elisa Gravito-Soares, es18497@gmail.com}

Accepted 20 November 2017

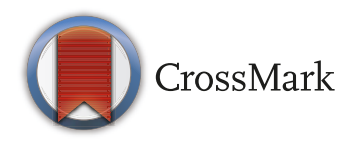

To cite: Gravito-Soares $\mathrm{E}$, Gravito-Soares M,

Cipriano MA, et al. BMJ Case Rep Published Online First: [please include Day Month Year]. doi:10.1136/bcr-2017223458

\section{DESCRIPTION}

A 47-year-old woman was diagnosed with systemic lupus erythematosus (SLE) at age 27 based on articular involvement (Jaccoud's arthropathy), lymphopaenia, thrombocytopaenia, pleuritis and positive antinuclear/anti-dsDNA antibodies. She was under azathioprine $75 \mathrm{mg}$ and mycophenolate mofetil $3 \mathrm{~g}$ daily. Renal involvement (diffuse proliferative glomerulonephritis) was diagnosed 2 months ago. She was admitted with a 2-week history of diarrhoea, abdominal pain and intermittent fever. Physical examination revealed lower abdominal discomfort and mild bilateral leg oedema. Laboratory analysis showed severe hypoalbuminaemia, pancytopaenia, elevated $\mathrm{C}$ reactive protein $(25.8 ; \mathrm{n}<0.5 \mathrm{mg} / \mathrm{dL})$ and normal coagulation tests. She had active disease Systemic lupus erythematosus disease activity index of 23 (SLEDAI-23), starting prednisolone $1 \mathrm{mg} / \mathrm{kg} /$ day and 5 -day course of intravenous immunoglobulin $2 \mathrm{~g} / \mathrm{kg} /$ day; mycophenolate mofetil dose was reduced $(2.5 \mathrm{mg}$ day). Infectious disease screening was negative, including cytomegalovirus (CMV) (IgM-/IgG+, negative serum CMV-DNA). Ileocolonoscopy showed a colorectal congestive/granular mucosa with erosions, friability and subepithelial haemorrhagic suffusions (figure $1 \mathrm{~A}-\mathrm{C}$ ). Biopsies revealed normal ileal mucosa and SLE-related pancolitis

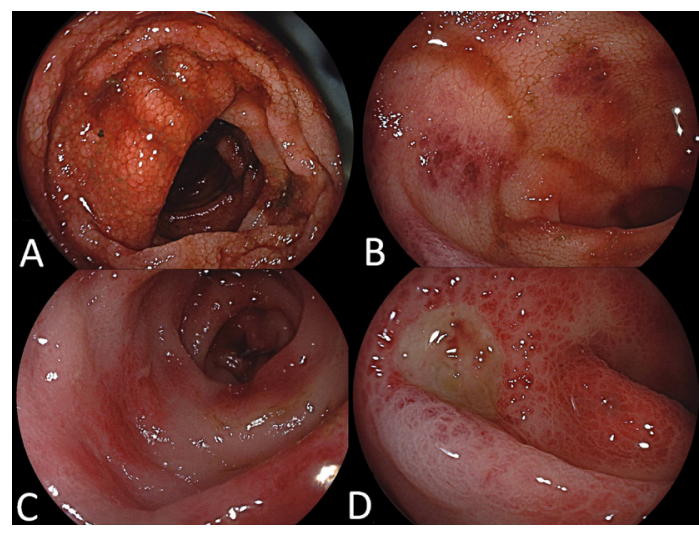

Figure 1 Endoscopic appearance of systemic lupus erythematosus-related colitis with a congestive and granular mucosa with friability, diffuse erosions and subepithelial haemorrhagic suffusions throughout the colon and rectum $(A, B, C)$, and subsequent colonoscopy with several cytomegalovirus-positive ulcers along the colon (D).

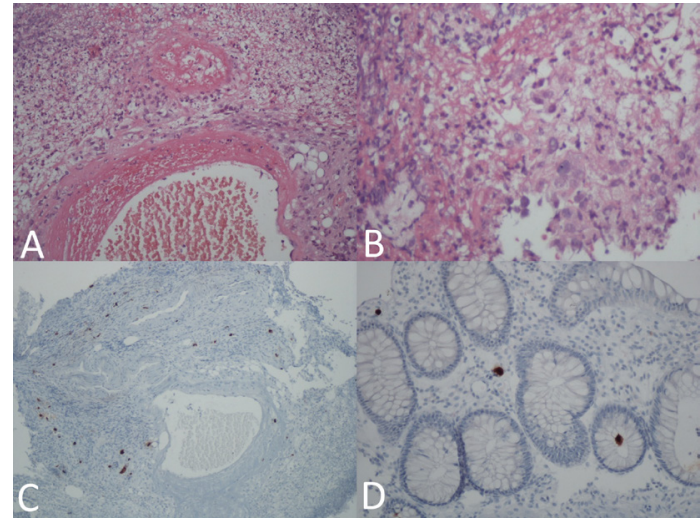

Figure 2 Histopathology of colonic biopsy specimens showing ischaemic and inflammatory subacute colitis with polymorphonuclear infiltrate (neutrophils and eosinophils), intense apoptosis, glandular necrosis and acute vasculitis, compatible with systemic lupus erythematosus-related colitis $(A, B)$; biopsies from the base and edge of colonic ulcers revealed cytomegalovirus-positive cells by immunohistochemical staining $(C, D)$.

(figure 2A,B). However, she worsened with febrile neutropaenia, increasing inflammatory parameters and chronic renal disease without exacerbation or oligoanuria. Infectious disease rescreening, including blood and urine cultures, was negative. Chest and plain abdominal X-rays were normal. Broad-spectrum antibiotics, 3-day course of intravenous methylprednisolone $500 \mathrm{mg}$, ciclosporin $150 \mathrm{mg} /$ day and filgrastim were added. Two weeks after admission, despite improvement in inflammatory parameters, she developed intermittent haematochezia with haemodynamic instability requiring daily blood components transfusion. Oesophagogastroduodenoscopy was normal. Colonoscopy was repeated showing vasculitis and several ulcers throughout the colon (figure 1D), the biopsies of which revealed CMV-positive cells (figure 2C,D). CMV serology was repeated with negative IgM, but elevated CMV-DNA (5 693532 copies/mL), starting intravenous ganciclovir $5 \mathrm{mg} / \mathrm{kg} /$ day. She continually worsened with severe anaemia (haemoglobin: $4-5 \mathrm{~g} / \mathrm{dL}$ ). Additional coagulopathies study was negative without evidence of disseminated intravascular coagulation. CT angiography showed mild diffuse colorectal wall thickening but no evidence of focal active bleeding, small bowel 


\section{Learning points}

- Systemic lupus erythematosus (SLE)-related colitis represents a rare and potentially life-threatening condition. This disease should be suspected in a patient with LES presenting with abdominal pain, diarrhoea and lower gastrointestinal bleeding.

- Endoscopy and histopathology are essential in SLE-related colitis diagnosis and the exclusion of superimposed conditions, including cytomegalovirus infection.

- Early diagnosis and prompt treatment are crucial to improve prognosis.

abnormalities or mesenteric vessels thrombosis. After the multidisciplinary team meeting, she underwent total proctocolectomy with terminal ileostomy. Histopathology of surgical specimen revealed a diffuse colorectal ischaemia and vasculitis compatible with SLE-related colitis with CMV superinfection. Due to bleeding from stoma, she was relaparotomised with resection and reconfection of ileostomy, with cessation of bleeding. The resected specimen revealed ischaemic ileostomy with normal ileal mucosa upstream of ileostomy, without involvement of surgical margins. Unfortunately, she died 1 day after proctocolectomy.

SLE represents an autoimmune inflammatory disease with multisystem involvement. Gastrointestinal symptoms are common in patients with SLE, often related to adverse drug reactions and infection. ${ }^{1}$ SLE-related colitis, as a consequence of lupus mesenteric vasculitis, is a rare $(0.2 \%-9.7 \%)$ and potentially life-threatening condition. ${ }^{1-3}$ Despite improvement with corticosteroids and immunosuppressive agents, ${ }^{12}$ there is an increased risk of serious superimposed infections as CMV infection. ${ }^{13} \mathrm{We}$ present the case of a fatal lower gastrointestinal bleeding caused by colitis associated with active SLE and complicated by CMV colitis despite immunosuppression intensification, target therapy for the identified infection and salvage proctocolectomy. Endoscopy and histopathology are essential in SLE-related colitis diagnosis and superimposed infection exclusion. Early diagnosis and prompt treatment are crucial to improve prognosis.

Contributors EG-S and MG-S contributed equally, writing the manuscript and reviewing the literature. EG-S is the article guarantor. MAC reviewed histopathological findings. PA critically reviewed the manuscript.

Competing interests None declared.

Patient consent Obtained.

Provenance and peer review Not commissioned; externally peer reviewed.

(C) BMJ Publishing Group Ltd (unless otherwise stated in the text of the article) 2017. All rights reserved. No commercial use is permitted unless otherwise expressly granted.

\section{REFERENCES}

1 Tian XP, Zhang X. Gastrointestinal involvement in systemic lupus erythematosus: insight into pathogenesis, diagnosis and treatment. World J Gastroenterol 2010;16:2971-7.

2. Nozari N, Divsalar P. Systemic lupus erythematosus presenting with a fatal intestinal vasculitis: a case report. Middle East J Dig Dis 2014;6:162-4.

3 Sakamoto O, Ando M, Yoshimatsu S, et al. Systemic lupus erythematosus complicated by cytomegalovirus-induced hemophagocytic syndrome and colitis. Intern Med 2002;41:151-5.

Copyright 2017 BMJ Publishing Group. All rights reserved. For permission to reuse any of this content visit

http://group.bmj.com/group/rights-licensing/permissions.

BMJ Case Report Fellows may re-use this article for personal use and teaching without any further permission.

Become a Fellow of BMJ Case Reports today and you can:

- Submit as many cases as you like

- Enjoy fast sympathetic peer review and rapid publication of accepted articles

- Access all the published articles

- Re-use any of the published material for personal use and teaching without further permission

For information on Institutional Fellowships contact consortiasales@bmjgroup.com

Visit casereports.bmj.com for more articles like this and to become a Fellow 